\title{
Psychological Perspective Theories of Harmony of Ethno-Religious Group Relation
}

\author{
Ichlas Nanang Afandi \\ Department of Psychology \\ Hasanuddin University \\ Makassar, Indonesia \\ ichlasafandi@yahoo.co.id
}

\begin{abstract}
During this period, study on ethno-religious group relations is more focused on the conflicts that occur between them. This condition then has implications for the many theoretical reviews about it. Theories that discuss about ethno-religious group conflict are very easy to find in various social science literatures, including psychology. In contrast to ethnic-religious group conflict, study about harmony of ethno-religious group relation are still rarely done so that it implies to the lack of theoretical reviews about it. Even if there is a theory, it does not explain comprehensively. Although, as a discipline, psychology has actually offered some theoretical concept that explain comprehensively about harmony of ethno-religious group relation. This paper aims to inform the public that the psychology, especially social psychology has long been concerned about harmony of ethno-religious group relation. Contact Theory, Cross Cutting Categorization Theory, Common Ingroup Identity Model Theory, and Cooperation and Competition Theory are some social psychology theories that discuss about harmony of ethno-religious group relation which will be describes systematically and concise in this paper.
\end{abstract}

Keywords - conflict; harmony; ethno-religious group; group relation; social psychology theory

\section{INTRODUCTION}

During this period, study on ethno-religious group relations is more focused on the conflicts that occur between them. This condition then has implications for the many theoretical reviews about it. Theories that discuss about ethno-religious group conflict are very easy to find in various social science literatures, including psychology. In contrast to ethnicreligious group conflict, study about harmony of ethnoreligious group relation are still rarely done so that it implies to the lack of theoretical reviews about it. Even if there is a theory, it does not explain comprehensively. Although, as a discipline, psychology has actually offered some theoretical concept that explain comprehensively about harmony of ethno-religious group relation.

In psychology literature, especially social psychology, there are many theories that discusses the harmony of intergroup relations. The contact theory, the cross cutting category theory, common ingroup identity model theory, and the theory of cooperative-competitive are some of the psychological theories in question. In fact, these theories have been widely applied and proven to be a reference in creating inter-group relation harmony. The harmony of inter-group relations is determined by several conditions, such as the presence of contacts between groups, there is a relatively similar perception of the world, self-categorization, cross categorization, or other group identities capable of accommodating the differences [1]. Even so, many people, academics and non-academics who do not know the existence of these theories. This is different from the theory of conflict between groups that are very familiar, both for academics and non-academics.

This fact is of course quite apprehensive, given the practical current, efforts to create a peaceful atmosphere between different groups more intensively conducted. Experts from various disciplines are involved to realize that expectation. As one of the recognized disciplines of its existence, psychology should play an active role in realizing that expectation, and one effort that can be done is to introduce psychological theories that talk about the harmony of inter-group relations.

The purpose of this paper is to introduce to the public that the science of psychology, especially social psychology, has quite a lot of theories that are concerned with the harmony of inter-group relations. Systematical and concise, contact theory, cross cutting category theory, common in-group identity model theory, and the theory of cooperativecompetitive will be described in this paper.

\section{Psychological Perspective Theories of Harmony ETHNO-RELIGIOUS GROUP}

\section{A. Inter-Group Relation}

Intergroup relation is a relationship between two or more groups, including the relationships between individuals within the group. Whenever members in a group interact, either individually or collectively with other group members, the current inter-event behavior occurs [2]

Furthermore, inter-group relationships as relationships that depend on the individual in a group perceiving, thinking, feeling, and behaving toward 
individuals in another group [3]. Intergroup relationships are on what is happening to individuals within a group, who care about their perceptions, ways of thinking, and behavior towards individuals within other groups [4].

\section{B. Harmony of Ethno Group Relation: Some Theoretical} Perspective

Inter-group harmony is positive relationships that are established among group members manifested in positive perceptions, attitudes, and behaviors among other group members (outgroup members), which creates peaceful conditions and conditions [5]. Here is a description of several theories that discuss about the harmony of ethnoreligious groups:

\section{Contact Theory}

The most basic theory that can be used to explain the harmony of ethno-religious group relation is contact theory [6]. This theory is one of the most important theories of social psychology when discussing the relations between ethno-religious groups. It is very difficult to ignore this theory when intergroup relationships will be discussed [6]. The proposition of this theory believes that contact (interaction) between members of two or more different groups (in some circumstances) will reduce prejudice and improve the quality of social relations [7].

The psychological aspects of the individual, such as empathy and self-disclosure play a very important role when interaction between groups takes place. Empathy and self-disclosure will improve the effectiveness of contacts (interaction) between groups [8]. Empathy is able to reduce differences between groups and place individuals from a group in the same position or category with individuals from other groups [9]. Self-disclosure between ethno-religious groups relation has a very positive effect on the quality of interracial relationship [10]. Self-disclosure is closely associated with positive interactions and relationships [11]. Self-disclosure is the way each individual of different groups to know each other and understand their beliefs and values more accurately [7].

\section{Cross Cutting Categorization Theory}

This theory developed from postulates of the social sciences, such as anthropology, sociology, political science, and social psychology who believe that the existence of orthogonal or crosscutting patterns of social category differences can reduce the occurrence of conflict in heterogeneous societies [12]. A cross category occurs when two people from different categories of social categories meet and then they manage to find at least one common category and make the similarity a means to keep relationships positive [13]. The crossing of social identity categories will help two different groups find a common ground of identities that is then used as a tool to reduce intergroup bias [14]. The crossing category as a potential tool to reduce bias between groups through two components, namely the cognitive component and the motivational component. Cognitive components by reducing perceptions of the many differences, while the motivational component by knowing further different groups [15].

\section{Common In-group Identity Model Theory}

The idea of this theory is constructed according to the meta-contrast principle which states that two groups can only be unified if the difference between the two is minimized or the equations between them are optimized [12]. The assumption of this theory is how to optimize the factors that can reduce the bias between groups by regenerating the self of each member from different groups into one self-categorization based on the same group [16]. Self-alignment will change the positive beliefs, feelings, and individual behaviors based on the new group's established system. If previously these are based on their own exclusive in-group system, then after categorization, they are based on a coherent inclusive ingroup system.

This theory believes that two distinct groups can be merged into one if each group member has an understanding that they are the same (on a particular aspect), having an inclusive (not exclusive) entity that will generate more positive beliefs, feelings, and behaviors one with another [16]. This theory also believes that the way to improve the quality of inter-group relations is to change the cognitive representation of each group member from two different groups. If before, the cognitive representations of the two groups are "us" and "them", then after being changed it will be an inclusive group with its cognitive representation being "us" [17].

\section{Theory of Cooperative-Competitive}

Ignorance, misunderstanding, categorization, and competition increase the stereotypes and negative perceptions between groups [18]. On the other hand, mutual understanding and cooperative cooperation can reduce biases between groups. Cooperative cooperation is a form of cooperation among members in a group (superordinate) done to achieve greater common goals [19].

Some research results indicate that in cooperative cooperation, rather than competitive cooperation, group members are more involved in the process and planning of group goals, so that the relationships are built and felt by them much warmer and more comfortable, and create a more collectivistic atmosphere. Atmosphere The conditions that make each group members more open to share information and more daring to discuss their different ideas so that the group climate becomes more conducive and effective [20].

Cooperative cooperation will develop a constructive culture of controversy or constructive competition, an open discussion culture ready to accept dissent for the achievement of a larger goal (group). In cooperative co- 
operation, each group member is able to see the differences more positively and constructively so that group issues can be solved by open discussion which results in more qualified solutions [21].

\section{CONCLUSION}

Psychology, especially social psychology, has provided quite a lot of theories that discuss the harmony of ethno-religious group. Contact theory, cross cutting categorization theory, common in-group identity model theory, and cooperative-competitive theory are some of the theories in question. This means that as a science, psychology has actually contributed to creating a peaceful atmosphere in a world that filled by diverse ethno-religious groups.

\section{REFERENCES}

[1] R.J. Crisp, \& S.R. Beck, Reducing Intergroup Bias: The Moderating Role of Ingroup Identification. Group Processes \& Intergroup Relations, 8 (2), 173-185. 2005

[2] M. Sherif, \& C.W. Sherif, Research in Intergroup Relations. Dalam O. Klineberg \& R. Christie. (Eds). Perspective in Social Psychology. New York : Holt, Rinehart \& Watson. 1965

[3] J. Delamater, Handbook of Social Psychology. New York : Springer. 2006

[4] A. Figueiredo, J.P. Valentim, J.P \& B. Doosje, Theories on Intergroup Relations and Emotions : A Theoritical Overview. Psyhologica, 57 (2), 7-33. 2014

[5] T. Saguy, N. Tausch, N, J.F. Dovidio, F. Pratto \& P. Singh, Tension and harmony in intergroup relations. Dalam M. Mikulincer, \& P. Shaver (Eds.), Understanding and reducing Aggression, Violence, and their Consequences. American Psychological Association. 2010

[6] J, Harwood \& N, Joyce, Intergroup Contact and Communication. Dalam Giles, H., The Handbook of Intergroup Coomunication (hal. 167-180). New York : Routledge, Taylor \& Francis. 2012

[7] J.A.C. Everett, Intergroup Contact Theory : Past, Present, and Future. The Inquisitive Mind Journal, 17. 2013

[8] T.F. Pettigrew \& L.R. Tropp, A Meta-Analytical Test of The Intergroup Contact Theory : Journal of Personality and Social Psychology, 90, 75I783. 2006
[9] S.L. Gaertner, J.F. Dovidio \& M.A. Houlette, Social Categorization. Dalam J.F. Dovidio,. M. Hewstone., P. Glick. \& V.M. Esses. (Eds). The Sage handbook of Prejudice, Stereotyping, and Discrimination. (hal. 526-543). Los Angeles : Sage. 2010

[10] J.N. Shelton, T.E. Trail, T.V. West, T.V. \& H.B. Bergsieker, From Strangers to Friend : The Interpersonal Proses of Intimacy in Developing Interaccial Friendship. Journal of Social and Personal Relationship, 27, 71-90. 2010

[11] A.M. Ledbetter, J.P. Mazer, J.M. De Groot, K.R. Meyer, Y. Mao \& B. Swafford, Attiitude Toward On-Line Social Connection and SelfDisclocure as Predictors of Fcebook Communication Relational Closeness. Communication Research, 38, 27-53. 2011

[12] R.J. Crisp, R.N. Turner \& M. Hewstone, Common Ingroups and Complex Identities:Routes to Reducing Bias in Multiple Category Contexts. Group Dynamics: Theory, Research, and Practice, 14 (1), 32 46. 2010

[13] D.I. Urada \& N. Miller, N, The Impact of Positive Affect on Crossed Categorization Effects. Journal of Personality and Social Psychology, 78 (3), 417-433. 2000

[14] N. Ensari, \& N. Miller, Decategorization and the reduction of bias in the crossed categorization paradigm. European Journal of Social Psychology, 31 (2), 193-216. 2001

[15] D.I. Urada, D.M. Stenstrom, \& N. Miller, Crossed Categorization Beyond the Two Group Paradigm. Journal of Personality and Social Psychology, 92, 649-664. 2006

[16] S.L Gaertner \& J.F. Dovidio, The Common Ingroup Identity Model. Dalam P.A.M. Van Lange, ., A.W. Kruglanski, \& E.T. Higgins, (Eds). Handbook of Theories of Social Psychology. London : Sage Publication. 2012

[17] S.L. Gaertner, J.A. Mann, A.J. Murrell \& J.F. Dovidio, Reducing Intergroup Bias: The Benefits of Recategorization. Journal of Personality and Social Psychology, 57, 239-249. 1989

[18] R. Brown, \& M. Hewstone, An Integrative Theory of Intergroup Contact. Advances in Experimental Social Psychology, 37, 255-343. 2005

[19] D.W. Johnson, D. W \& R.T. Johnson, Cooperation and Competition: Theory and Research. Edina, MN: Interaction Book Co. 1989

[20] C.K.W. De Dreu, Cooperative Outcome Interdependence, Task Reflexivity, and Team Effectiveness : A Motivated Information Processing Perspective. Journal of Applied Psychology, 92 (30, 628638. 2007

[21] D. Tjosvold, Cooperative and Competitive Goal Approaches to Conflict: Accomplishments and Challenges. Applied Psychology: An International Review, 47, 285-342. 1998 